\title{
Valuation with mixed financing strategies
}

\author{
Stefan Dierkes $^{1}$ (D) Imke de Maeyer $^{1}$
}

Received: 6 January 2020/ Accepted: 26 September 2020/Published online: 15 October 2020

(C) The Author(s) 2020

\begin{abstract}
In corporate valuation, it is common to assume either passive or active debt management. However, it is questionable whether these pure financing policies reflect the real financing policies of firms with a sufficient degree of accuracy. This shortcoming has led to the development of mixed financing strategies as combinations of pure financing strategies. Whereas hybrid financing is directly linked to the two-phase model, it is unclear how to apply discontinuous financing in such a setting. In this study, according to the two versions of hybrid financing, we analyze the implementation of discontinuous financing in a two-phase model. Thereby, we present a simpler and more intuitive derivation of the valuation equation for discontinuous financing to increase its acceptance and its use for corporate valuation practice. Moreover, we compare the different mixed financing strategies with each other theoretically, and we conduct simulations to elucidate the impact on market values and the sensitivities of input parameters. The study concludes that the presented mixed financing strategies can help in the attempt to reflect the real financing behavior of firms more accurately and, therefore, constitute a valuable alternative to pure financing strategies for valuation.
\end{abstract}

Keywords Valuation · Financing strategy $\cdot$ Mixed financing strategy $\cdot$ Hybrid financing $\cdot$ Discontinuous financing $\cdot$ Two-phase model

JEL Classification G12 - G32

Stefan Dierkes

stefan.dierkes@wiwi.uni-goettingen.de

Imke de Maeyer

imke.demaeyer@uni-goettingen.de

1 Finance and Control, Georg-August-University-Göttingen, Platz der Göttinger Sieben 3, 37073

Göttingen, Germany 


\section{Introduction}

Corporate valuation with discounted cash flow approaches requires assumptions about the firm's financing strategy. Since interest on debt is deductible from taxable income, the financing strategy has an immediate influence on the market value of the firm. In this regard, it is generally assumed that a consistent financing strategy is pursued in each period of the forecast horizon. However, empirical findings show that it is questionable whether pure financing strategies like active or passive debt management reflect the real financing policies of firms with a sufficient degree of accuracy (see, e.g. Lewellen and Emery 1986; Barclay and Smith 2005; Grinblatt and Liu 2008). Therefore, it is promising to consider a two-phase model that differentiates between financing policies in the explicit forecast and the steady-state phase. The interaction between passive debt management in the explicit forecast phase and active debt management in the steady-state phase has already been examined as hybrid financing (Kruschwitz et al. 2007; Dierkes and Gröger 2010). Furthermore, discontinuous financing as another mix of active and passive debt management was developed (Clubb and Doran 1995; Arnold et al. 2018, 2019), but it has been of little relevance for corporate valuation practice so far and it is unclear how to apply this financing strategy in a two-phase model.

The contribution of this paper is threefold. First, we transfer the approach of hybrid financing to a two-phase model with passive debt management and discontinuous financing, which results in two new mixed financing strategies. Second, in the course of analyzing these new mixed financing strategies, we present a much-simplified derivation of the valuation equation for discontinuous financing. This more intuitive derivation could increase the acceptance of discontinuous financing and, therefore, its use for corporate valuation practice. Third, we compare hybrid and discontinuous financing as possible mixed financing strategies. We determine the deviations of the market values theoretically and analyze the distribution of the deviations and the influence of input parameters to investigate the impact and the relevance of these financing strategies for corporate valuation practice using a Monte Carlo simulation.

Although active and passive debt management are popular in corporate valuation practice, empirical studies indicate that these or other pure financing strategies are not suitable for modeling a firm's financing policy with a sufficient degree of accuracy; see, for example, Lewellen and Emery (1986); Barclay and Smith (2005); Grinblatt and Liu (2008). In particular, there exists a wide variety of theories on the capital structure behavior of firms (for a summary of empirical results on the capital structure research, see, e.g. Graham and Leary 2011). Theories on capital structure weigh the tax benefits that result from debt financing (see, e.g. Graham 2000) against the costs of financial distress (see, e.g. Molina 2005; Glover 2016) or agency and information costs (see, e.g. Copeland et al. 2014, pp. 413-462). In addition, the payout policy is a relevant factor since firms want to choose the optimal method to return capital to their investors (see, e.g. Berk and DeMarzo 2017, pp. 519-669). Furthermore, for a company, not only the amount of debt borrowed but also the type of debt is essential (see, e.g. Brealey et al. 2020, pp. 631-662). 
The actual financing behavior of firms is also influenced by a large number of other circumstances. For example, Bhamra et al. (2010) and Graham et al. (2015) showed that the development of financing policies depends on a wide range of macroeconomic factors, while Kayhan and Titman (2007) concluded that a firm's history has an important influence on its capital structure. Moreover, Graham and Harvey (2001) conducted a survey on 392 chief financial officers in the US and showed that only $10 \%$ of all firms have a strict target debt ratio, whereas $34 \%$ "have a somewhat tight target or range" (Graham and Harvey 2001, p. 211). The remaining firms either have a flexible target or have no target debt ratio at all (Graham and Harvey 2001, p. 211). Brounen et al. (2006) continued this research by comparing its results to those of selected countries in Europe. Their study showed "that in each of the countries merely $10 \%$ of all firms maintain a strict target" (Brounen et al. 2006, p. 1430), supporting the findings of Graham and Harvey (2001). Similar results can be found in de Jong and Verwijmeren (2010), who conducted a survey on 235 firms in the US, Canada, and Europe and used it for empirical model testing. They found that $55 \%$ of firms have a mostly flexible target (de Jong and Verwijmeren 2010, p. 220).

This variety of theories and findings play an important role for corporate valuation since the assumption of a financing strategy should depict the real financing behavior of firms as accurately as possible. Grinblatt and Liu (2008) summarized these and other results as follows: "The actual debt policies of firms tend to deviate from those specified by the Modigliani-Miller and Miles-Ezzell models" (Grinblatt and Liu 2008, p. 226). For corporate valuation, it follows that one can either accept the resulting valuation inaccuracy or attempt to depict a firm's financing policy more accurately to achieve more precise valuation results. This yields the concept of mixed financing strategies that combine two or more pure financing strategies and, therefore, have more degrees of freedom to describe a firm's financing policy. However, an additional requirement for a financing strategy is that it is intuitive and applicable. It follows that mixed financing strategies are developed to get closer to the real financing behavior of firms but are still a simplified representation and cannot consider all theories and findings. Otherwise, the resulting model would be too complex. In this study, we concentrate on mixed financing strategies in a two-phase model with passive debt management in the explicit forecast period.

Kruschwitz et al. (2007) were the first to discuss the application of passive debt management in the explicit forecast phase and active debt management in the steady-state phase under the term hybrid financing. They outlined that debt levels of firms are observed to be largely fixed in the early years of the planning phase, particularly due to fixed investment planning. It follows that debt financing can be adjusted only to a limited extent following active debt management in the first $T$ periods. Meanwhile, a deterministic definition of debt levels at the time of valuation in periods further away appears to be equally unrealistic, thereby impairing the plausibility of passive debt management in these periods (Kruschwitz et al. 2007). Dierkes and Gröger (2010) continued this research by pointing out that a distinction can be made regarding the definition of the debt-to-market value ratio of active debt management in the steady state. On the one hand, it is possible to 
define the leverage ratio deterministically at the time of valuation, which is referred to as L-hybrid financing and complies with the financing strategy of Kruschwitz et al. (2007). On the other hand, D-hybrid financing is possible, whereby the debt level in period $T$ is defined deterministically at the valuation date. Therefore, the leverage ratio of the steady-state phase results from the deterministic debt level and the uncertain market value at the end of the explicit forecast phase. The abbreviations $\mathrm{L}$ and $\mathrm{D}$ stand for leverage and debt, respectively. These combinations of active and passive debt management yield different financing strategies, which in turn yield different valuation results (Dierkes and Gröger 2010).

Discontinuous financing considers other shortcomings of pure active and passive debt management. Particularly, discontinuous financing picks up on empirical research that indicates that firms adjust their debt levels very slowly (Fama and French 2002) and only with a time lag (Leary and Roberts 2005; Huang and Ritter 2009). Originally, Clubb and Doran (1995) introduced discontinuous financing under the term lagged debt management policy. This financing strategy consists of passive debt management that is adapted to the development of the firm after a limited number of periods. We call these periods a planning phase. Thus, debt levels are defined deterministically only for one planning phase. They are derived by multiplying the expected market values of the firm by a debt-to-market value ratio. After such a planning phase, the debt levels are again defined deterministically considering changes in the economic environment using the updated expected market values. It is important to observe that despite the use of a debt ratio, the debt levels are certain within a planning phase, since they are linked to the debt-tomarket value ratio according to the expected - not realized-market values of the firm (Ashton and Atkins 1978). Furthermore, contrary to hybrid financing, which is characterized by one switch from passive to active debt management, discontinuous financing "allows for shifts in both directions for several times" (Arnold et al. 2018 , p.151) and thereby relaxes the assumption of hybrid financing. An extension of the lagged debt management policy of Clubb and Doran (1995) was introduced by Arnold et al. (2018) who referred to it as discontinuous financing since it extends active debt management according to $\mathrm{ME}$ "by a discontinuous refinancing sequence" (Arnold et al. 2018, p. 150). Specifically, they pursued the second approach of Clubb and Doran (1995) that keeps debt constant between rescheduling, and conducted their analysis for the case of a perpetuity. Arnold et al. (2019) enhanced the valuation formula to a perpetuity with a constant growth rate. Since we pick up on the research of Arnold et al. (2018) we use the term discontinuous financing instead of lagged debt management.

Although discontinuous financing is a recognized concept in the literature of corporate valuation, it is so far of little relevance for corporate valuation practice. In this study, we present a simplified derivation of the valuation equation for the approach that Arnold et al. (2018) pursued. This simplified derivation is more intuitive and enhances the understanding of discontinuous financing. Therefore, it might make this concept more accessible for corporate valuation practice. The key is to use a recursive setting and apply the relation of the market values at the beginning of each planning phase. To consider the detailed forecast analysis of firms in early periods of their planning horizon, we combine discontinuous financing with 
an explicit forecast phase where passive debt management is used. To do so, we transfer the approaches of L- and D-hybrid financing to discontinuous financing. This approach leads to the development of two new mixed financing strategies, which we refer to as L-discontinuous and D-discontinuous financing. As above, the abbreviations $\mathrm{L}$ and $\mathrm{D}$ stand for leverage and debt, respectively. L-discontinuous financing is characterized by a deterministic definition of the leverage ratio at the time of valuation. In the case of D-discontinuous financing, the debt level in period $T$ is defined deterministically at the valuation date.

We analyze the effects on the market value of these new financing strategies theoretically and with the help of a simulation. Furthermore, we compare L- and D-discontinuous financing to L- and D-hybrid financing, and to pure active and passive debt management, respectively. With the help of the simulation analysis, we can not only determine the distributions of the deviations of the market values but also estimate the influence of different input parameters. Thereby, we expand the example of Arnold et al. (2018) who compare firm values under discontinuous financing for various lengths of planning phases and three different debt-to-market value ratios. We conclude that the use of mixed financing strategies constitutes a reasonable and promising alternative to pure financing strategies in depicting the financing behavior of a firm. Particularly, hybrid financing or discontinuous financing in a two-phase model solves some shortcomings of active and passive debt management.

The remainder of this study is structured as follows. The next section offers an analysis of passive and active debt management in a two-phase model by presenting valuation equations under L- and D-hybrid financing. This constitutes the basis for the development of a two-phase model that includes discontinuous financing, which results in L- and D-discontinuous financing. In Sect. 3, the mixed financing strategies are compared theoretically and the results are illustrated by simulations. Finally, the possibility of using mixed financing is discussed from theoretical and practical viewpoints.

\section{Mixed financing strategies in a two-phase model}

\subsection{Valuation with hybrid financing}

Since we want to transfer the approach of $\mathrm{L}$ - and D-hybrid financing to discontinuous financing, we need to analyze the concept of hybrid financing first. The construction is based on a two-phase model. In the explicit forecast phase, passive debt management is used, whereas in the steady-state phase, active debt management is assumed (Kruschwitz et al. 2007). The distinction between L- and $\mathrm{D}$-hybrid is made by different ways of determining the debt-to-market value ratio of the steady-state phase (Dierkes and Gröger 2010).

We assume that the explicit forecast phase consists of $T$ periods. After this first phase, the firm is situated in a steady state. In this second phase, all variables associated with the valuation increase at a uniform and constant growth rate $g$. In addition, we suppose that the business risk does not change over time, which results 
in a constant cost of equity of the unlevered firm $\rho^{u}$. Since it is not the focus of our analysis, the costs of financial distress and the possibility of default are not considered such that the cost of debt corresponds to the risk-free interest rate $r$. This strong assumption can easily be relaxed by considering the cost of debt instead of the risk-free interest rate as it is done in Clubb and Doran (1995) and Arnold et al. (2018). ${ }^{1}$ Moreover, it is assumed that interest on debt is fully deductible from taxable income.

We start with the analysis of L-hybrid financing. The abbreviation L refers to leverage. Under this financing strategy, we suppose that the debt-to-market value ratio $\theta$ and, therefore, the leverage $L$ of active debt management, which is used in the steady-state phase, is determined at the time of valuation; see Fig. 1. By combining the adjusted present value (APV) approach (Kruschwitz and Löffler 2020, p. 90) for the explicit forecast phase with the free cash flow (FCF) approach (Kruschwitz and Löffler 2020, pp. 101-103) for the steady-state phase, the following valuation equation for L-hybrid financing (Kruschwitz et al. 2007, p. 429; Dierkes and Gröger 2010, p. 60) is obtained:

$$
V_{0}^{\ell, \mathrm{LH}}=\sum_{t=1}^{T} \frac{\mathbb{E}\left[\widetilde{F C F}_{t}\right]}{\left(1+\rho^{u}\right)^{t}}+\sum_{t=1}^{T} \frac{\tau \cdot r \cdot D_{t-1}}{(1+r)^{t}}+\frac{\mathbb{E}\left[\widetilde{F C F}_{T+1}\right]}{\left(k^{\tau}-g\right) \cdot\left(1+\rho^{u}\right)^{T}},
$$

where $\tau$ denotes the corporate tax rate; $F C F_{t}$ the free cash flow, which is the cash flow of the unlevered firm; $D_{t}$ the amount of debt; and $V_{t}^{\ell}$ the market value of the levered firm at the end of period $t$. The abbreviation LH refers to L-hybrid financing.

The valuation equation can be interpreted as follows. In the first term, the market value of the unlevered firm in the explicit forecast phase is computed by discounting the FCFs at the cost of equity of an unlevered firm. In the second term, we add the value of the tax shields of the first $T$ periods. Since we assume passive debt management in this phase, the tax shields can be discounted at the risk-free interest rate. The term $\frac{\widetilde{\mathbb{E}\left[F C F_{T+1}\right]}}{k^{\tau}-g}$ determines the terminal value of a perpetual annuity with growth under active debt management at the beginning of the steady-state phase. In accordance with the FCF approach, the discounting is conducted with the weighted average cost of capital $k^{\tau}=\rho^{\ell} \cdot(1-\theta)+r \cdot(1-\tau) \cdot \theta$, where $\rho^{\ell}$ represents the cost of equity of a levered firm. Since ME showed that the market value of a levered firm and the market value of an unlevered firm of one period differ only by a factor that is already known at the valuation date, we can use the cost of equity of an unlevered firm to discount the terminal value to the valuation date (Miles and Ezzell 1980; Kruschwitz et al. 2007, p. 429; Dierkes and Gröger 2010, pp. 60-61). This formula applies to both active debt management according to ME and active debt

\footnotetext{
1 The discount rate to compute the market value of the tax shield depends on assumptions regarding the tax treatment. Depending on the taxation in the case of default, differences in the market value occur, see, for example, Sick (1990); Kruschwitz et al. (2005); Rapp (2006); Krause and Lahmann (2016); Baule (2019). A more explicit consideration of the insolvency risk for discontinuous financing can be found in Arnold et al. (2019).
} 


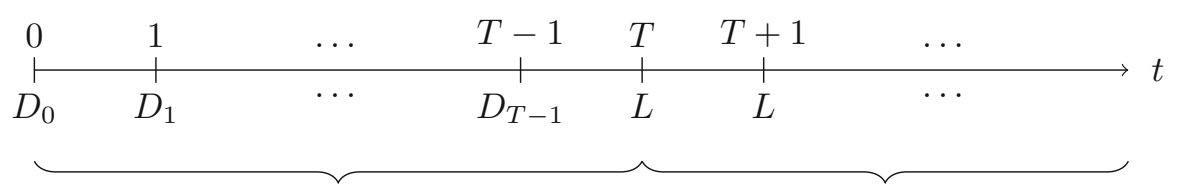

passive debt management active debt management

Fig. 1 L-hybrid financing: the leverage of the steady-state phase is determined at the valuation date

management according to HP, since one can select the corresponding adjustment formula for calculating the cost of equity of the levered firm. ${ }^{2}$

Defining the leverage $L$ and, therefore, the debt-to-market value ratio $\theta$ at the time of valuation can lead to substantial refinancing at the beginning of the steadystate phase since the debt level at the end of the explicit forecast phase $D_{T-1}$ may differ significantly from the debt level $\widetilde{D}_{T}=\theta \cdot \widetilde{V}_{T}^{\ell, \mathrm{LH}}$, which is determined according to active debt management in the first period of the steady-state phase. For an example that illustrates this refinancing, see Dierkes and Gröger (2010). This disadvantage of L-hybrid financing is compensated by D-hybrid financing, in which the debt level of period $T$ is defined deterministically. Thus, the leverage of the steady-state phase results from this deterministic debt level and the uncertain market value at the end of the explicit forecast phase. The abbreviation $\mathrm{D}$ refers to debt. This approach has the advantage that no refinancing is necessary at the end of the first forecast phase, such that a smoother transition from the explicit forecast phase to the steady-state phase is achieved. However, it has the disadvantage that the debtto-market value ratio of the steady-state phase is uncertain from the perspective of the valuation date and can vary depending on the realized state (Dierkes and Gröger 2010, pp. 59, 63-64). Figure 2 shows that in the case of D-hybrid financing, the debt level of period $T$ has to be additionally determined autonomously to calculate the debt-to-market value ratio. It follows that the debt-to-market value ratio of the steady-state phase is defined deterministically at the beginning of the steady-state phase rather than at the beginning of the explicit forecast phase, as in the case of L-hybrid financing.

By applying the APV approach for the explicit forecast and the steady-state phase, one obtains the valuation equation for D-hybrid financing (Dierkes and Gröger 2010, p. 63)

\footnotetext{
${ }^{2}$ In the case of active debt management according to HP, all tax shields are uncertain which yields the adjustment formula for the levered cost of equity $\rho^{\ell}=\rho^{u}+\left(\rho^{u}-r\right) \cdot L$ (Harris and Pringle 1985). Under active debt management of ME, the tax shields are certain in the period of their emergence and uncertain in all other periods, which yields $\rho^{\ell}=\rho^{u}+\left(\rho^{u}-r\right) \cdot \frac{1+r \cdot(1-\tau)}{1+r} \cdot L$ (Miles and Ezzell 1985).
} 


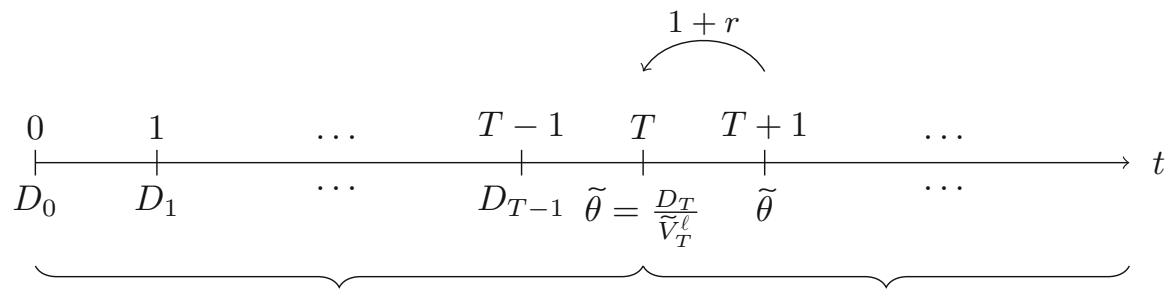

passive debt management

active debt management

Fig. 2 D-hybrid financing: the debt-to-market value ratio of the steady-state phase results from the deterministic debt level and the uncertain market value at the end of the explicit forecast phase

$$
\begin{aligned}
V_{0}^{\ell, \mathrm{DH}}= & \sum_{t=1}^{T} \frac{\mathbb{E}\left[{\widetilde{F C F_{t}}}_{t}\right.}{\left(1+\rho^{u}\right)^{t}}+\sum_{t=1}^{T} \frac{\tau \cdot r \cdot D_{t-1}}{(1+r)^{t}}+\frac{\mathbb{E}\left[\widetilde{F C F}_{T+1}\right]}{\left(\rho^{u}-g\right) \cdot\left(1+\rho^{u}\right)^{T}} \\
& +\frac{\tau \cdot r \cdot D_{T}}{\left(\rho^{u}-g\right)(1+r)^{T}},
\end{aligned}
$$

where DH stands for D-hybrid financing. Analogous to L-hybrid financing, the value of the firm in the explicit forecast phase is calculated in the first two terms. The computation of the terminal value is divided into the computation of the terminal value of the unlevered firm in the third term and the computation of the terminal value of the tax shields in the last term. The former is calculated by discounting the constantly growing FCF at the unlevered cost of equity $\rho^{u}$, which results in the formula for a perpetual annuity with growth $\rho^{u}-g$. The denominator is multiplied by $\left(1+\rho^{u}\right)^{T}$ to obtain the value at the valuation date. Unlike Eq. (1) that applies to active debt management according to ME and HP, this valuation equation only applies to active debt management according to HP. In this case, the tax shields of the steady state are uncertain in all periods and have to be discounted at the cost of equity of an unlevered firm. Furthermore, the tax shields grow at the constant growth rate $g$ such that they are also discounted using the formula $\rho^{u}-g$. Since the debt level $D_{T}$ is already known at the valuation date, the terminal value of the tax shields at time $T$ is discounted to the valuation date at the risk-free interest rate. If active debt management according to ME was used in the steady-state phase, discounting the tax shield of one period to the preceding period can be conducted using the risk-free interest rate $r$ instead of $\rho^{u}$. It follows that the terminal value of the tax shields needs to be multiplied by the factor $\frac{1+\rho^{u}}{1+r}$ (Miles and Ezzell 1980; Dierkes and Gröger 2010, p. 63).

In the remainder of this subsection, we theoretically compare the market values in the case of L- and D-hybrid financing. To do so, we require that either active debt management of ME or active debt management of HP is used for the steady-state phase in both cases. Furthermore, we assume that the expected debt-to-market value ratio of D-hybrid financing coincides with the deterministic debt-to-market value ratio of L-hybrid financing, that is, 


$$
\theta=\frac{D_{T}}{\mathbb{E}\left[\widetilde{V}_{T}^{\ell, \mathrm{DH}_{3}}\right]} .
$$

It follows that the tax shields of the steady-state phase coincide such that the terminal value of the tax shields at the beginning of the steady-state phase is the same for both financing strategies:

$$
\mathbb{E}\left[\widetilde{V}_{T}^{T S, \mathrm{LH}}\right]=\mathbb{E}\left[\widetilde{V}_{T}^{T S, \mathrm{DH}}\right] .
$$

The value of the unlevered firm does not depend on the financing strategy, such that the terminal value of the levered firm is identical:

$$
\mathbb{E}\left[\widetilde{V}_{T}^{\ell, \mathrm{LH}}\right]=\mathbb{E}\left[\widetilde{V}_{T}^{\ell, \mathrm{DH}}\right] .
$$

Although, the market values coincide at the beginning of the steady-state phase, the market values differ at the valuation date. The value difference of L- and D-hybrid financing lies in the discounting of the terminal values to the valuation date. This results in a higher value under D-hybrid financing than under L-hybrid financing since not the entire residual value is discounted at the unlevered cost of equity but only the value of the unlevered firm. The value of the tax shield at the beginning of the steady-state phase can be discounted using the lower risk-free interest rate, which yields a higher tax shield at the valuation date in the case of D-hybrid financing than in the case of L-hybrid financing. We exclude the explicit forecast phase and consider only value differences that result from the discounting of the terminal value to the valuation date. To do so, we introduce the notation $T V_{0}$ and deduce

$$
T V_{0}^{\ell, \mathrm{DH}}>T V_{0}^{\ell, \mathrm{LH}}
$$

Thus, the terminal value under D-hybrid financing is always higher than that under L-hybrid financing at the valuation date if the debt-to-market value ratios coincide. Table 1 summarizes these results.

\subsection{Valuation with discontinuous financing}

In this subsection, we examine the possibility of using discontinuous financing in the steady-state phase and passive debt management in the explicit forecast phase. To specify discontinuous financing, we follow the approach of Arnold et al. (2018) but present a simpler and more intuitive derivation of the valuation equation, which could increase its acceptance and its use for corporate valuation practice. Discontinuous financing consists of consecutive planning phases in which passive debt management is used. At the beginning of each planning phase, a refinancing is carried out. We determine the debt level at some refinancing date by multiplying the debt-to-market value ratio by the expected market value of the levered firm. Since we consider a steady state, it is assumed that this debt level, as well as the FCF, grows at a constant growth rate within the subsequent planning phase. After the 
Table 1 Comparison of the terminal values of the unlevered firm, the tax shields and the levered firm under L- and D-hybrid financing for the case of coinciding debt-to-market value ratios at time $T$ and at the valuation date

\begin{tabular}{|c|c|c|c|c|}
\hline & & \multicolumn{2}{|l|}{$\mathrm{LH}$} & DH \\
\hline \multicolumn{5}{|c|}{ Time $T$} \\
\hline & $\begin{array}{l}\text { TV unlevered } \\
\text { firm }\end{array}$ & $\mathbb{E}\left[\widetilde{V}_{T}^{u}\right]$ & $=$ & $\mathbb{E}\left[\widetilde{V}_{T}^{u}\right]$ \\
\hline+ & TV tax shields & $\mathbb{E}\left[\widetilde{V}_{T}^{T S, \mathrm{LH}}\right]$ & $=$ & $V_{T}^{T S, \mathrm{DH}}$ \\
\hline$=$ & TV levered firm & $\mathbb{E}\left[\widetilde{V}_{T}^{\ell, \mathrm{LH}}\right]$ & $=$ & $\mathbb{E}\left[\widetilde{V}_{T}^{\ell, \mathrm{DH}}\right]$ \\
\hline \multirow{2}{*}{\multicolumn{2}{|c|}{$\begin{array}{l}\text { TV TS is discounted at } \\
\text { Time } 0\end{array}$}} & $\rho^{u}$ & & $r$ \\
\hline & & & & \\
\hline & $\begin{array}{l}\text { TV unlevered } \\
\text { firm }\end{array}$ & $T V_{0}^{u}$ & $=$ & $T V_{0}^{u}$ \\
\hline+ & TV tax shields & $T V_{0}^{T S, \mathrm{LH}}$ & $<$ & $T V_{0}^{T S, \mathrm{DH}}$ \\
\hline$=$ & TV levered firm & $T V_{0}^{\ell, \mathrm{LH}}$ & $<$ & $T V_{0}^{\ell, \mathrm{DH}}$ \\
\hline
\end{tabular}

planning phase, the next refinancing is carried out by adjusting the debt levels according to the updated expected market values.

If we combine passive debt management in the explicit forecast phase with discontinuous financing, the debt levels are defined deterministically for the first $T$ periods. After these periods, the firm reaches a steady state, and the debt levels must be defined deterministically for the upcoming planning phase. Although the number of periods of this planning phase can generally be chosen arbitrarily, it is plausible that it is again possible to define the debt levels deterministically for $T$ periods and so on. Therefore, we link the number of periods of a planning phase to the number of periods $T$ of the explicit forecast phase, which can then be interpreted as the first planning phase, see Fig. 3. Regarding the specification of the debt-tomarket value ratio of the steady-state phase, we can make the same distinction as in the previous subsection. On the one hand, the debt-to-market value ratio can be determined at the time of valuation analogous to L-hybrid financing, which is referred to as L-discontinuous financing, where L stands again for leverage. On the

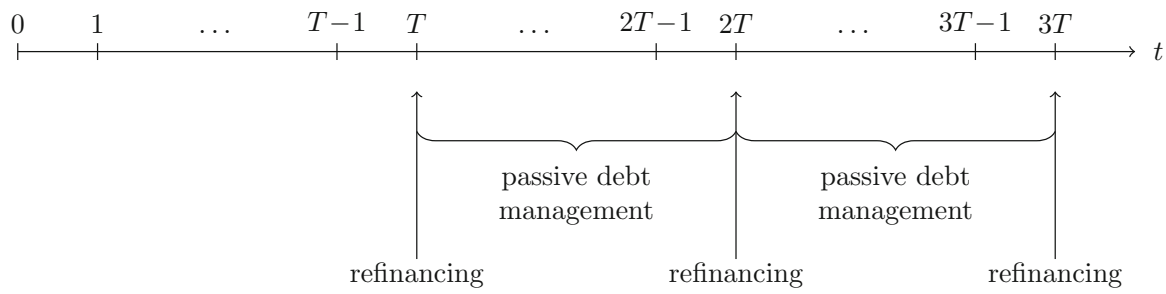

Fig. 3 Discontinuous financing in the steady-state phase 
other hand, analogous to a D-hybrid financing strategy, the debt-to-market value ratio that arises at the end of the explicit forecast phase can be used, which yields the development of a D-discontinuous financing strategy. As in the previous subsection, D stands for debt. The deterministic debt-to-market value ratio or the arising debt-to-market value ratio in the case of L- or D-discontinuous financing, respectively, is then used for the definition of debt levels in all subsequent planning phases.

First, we consider the case of L-discontinuous financing, which implies that the debt-to-market value ratio is defined deterministically at the valuation date. In contrast to Arnold et al. (2018), we choose a recursive approach to compute the market value under discontinuous financing. Using the APV method, we obtain the value of the levered firm at the beginning of the steady-state phase as

$$
\begin{aligned}
\mathbb{E}\left[\widetilde{V}_{T}^{\ell, \mathrm{LD}}\right]= & \sum_{t=1}^{T} \frac{\mathbb{E}\left[\widetilde{F C F}_{T+1}\right] \cdot(1+g)^{t-1}}{\left(1+\rho^{u}\right)^{t}}+\sum_{t=1}^{T} \frac{\tau \cdot r \cdot \theta \cdot \mathbb{E}\left[\widetilde{V}_{T}^{\ell, \mathrm{LD}}\right] \cdot(1+g)^{t-1}}{(1+r)^{t}} \\
& +\frac{\mathbb{E}\left[\widetilde{V}_{2 T}^{\ell, \mathrm{LD}}\right]}{\left(1+\rho^{u}\right)^{T}},
\end{aligned}
$$

where LD stands for L-discontinuous financing. The valuation equation can be interpreted as follows. In the first term, the value of the unlevered firm in the first planning phase of the steady state is determined by discounting the FCFs at the cost of equity of an unlevered firm. In the second term, the value of the tax shields in the first planning phase is computed. Since the debt levels are certain within a planning phase, the risk-free interest rate is the appropriate discount factor. Finally, the value of the levered firm at the beginning of the second planning phase is added and, according to $\mathrm{ME}$, discounted at the cost of equity of an unlevered firm. This expression can be simplified using the annuity present value factor for a constantly growing cash flow to

$$
\begin{aligned}
\mathbb{E}\left[\widetilde{V}_{T}^{\ell, \mathrm{LD}}\right]= & \mathbb{E}\left[\widetilde{F C F}_{T+1}\right] \cdot \operatorname{APV}\left(\rho^{u}, g, T\right) \\
& +\tau \cdot r \cdot \theta \cdot \mathbb{E}\left[\widetilde{V}_{T}^{\ell, \mathrm{LD}}\right] \cdot \operatorname{APV}(r, g, T)+\frac{\mathbb{E}\left[\widetilde{V}_{2 T}^{\ell, \mathrm{LD}}\right]}{\left(1+\rho^{u}\right)^{T}},
\end{aligned}
$$

where

$$
\operatorname{APV}(k, g, T)=\frac{1}{k-g} \cdot\left(1-\frac{(1+g)^{T}}{(1+k)^{T}}\right)
$$

is the annuity present value factor. So far, this valuation equation is of little use since it contains the market value at the beginning of the second phase, that is, the market value in period $2 T$. However, since the free cash flow as well as the debt level grow at a constant growth rate $g$, the value of the levered firm also increases at this rate such that we obtain 


$$
\mathbb{E}\left[\widetilde{V}_{2 T}^{\ell, \mathrm{LD}}\right]=\mathbb{E}\left[\widetilde{V}_{T}^{\ell, \mathrm{LD}}\right] \cdot(1+g)^{T} .
$$

This relation is crucial for our analysis, and its use makes the derivation of the valuation equation much easier compared to Arnold et al. (2018). Inserting Eq. (10) into Eq. (8) and solving the circularity problem, that is, solving for the market value of the firm $\mathbb{E}\left[\widetilde{V}_{T}^{\ell, \mathrm{LD}}\right]$, results in

$$
\mathbb{E}\left[\widetilde{V}_{T}^{\ell, \mathrm{LD}}\right]=\frac{\mathbb{E}\left[\widetilde{F C F}_{T+1}\right] \cdot \operatorname{APV}\left(\rho^{u}, g, T\right)}{1-\tau \cdot r \cdot \theta \cdot \operatorname{APV}(r, g, T)-\frac{(1+g)^{T}}{\left(1+\rho^{u}\right)^{T}}} .
$$

By multiplying the numerator by $\frac{\rho^{u}-g}{\rho^{u}-g}$, Eq. (11) can be reduced to

$$
\mathbb{E}\left[\widetilde{V}_{T}^{\ell, \mathrm{LD}}\right]=\frac{\mathbb{E}\left[\widetilde{V}_{T}^{u}\right]}{1-\theta \cdot \Gamma^{T, g}},
$$

where

$$
\Gamma^{T, g}=\frac{\tau \cdot r \cdot \operatorname{APV}(r, g, T)}{\operatorname{APV}\left(\rho^{u}, g, T\right) \cdot\left(\rho^{u}-g\right)} .
$$

Since the annuity present value factor is the reciprocal of the annuity factor, this result is consistent with the valuation equation of Arnold et al. (2018) and Arnold et al. (2019). Thus, by applying a recursive approach and the help of Eq. (10), we obtain a simplified and more intuitive derivation for this valuation equation, which easily shows how the factor $\Gamma^{T, g}$ is derived.

Note that the marginal cases of valuation Eq. (11) display well-known pure financing strategies. For $T \rightarrow \infty$, the valuation equation simplifies to the valuation equation of passive debt management since there is only one infinitely long planning phase in which the debt levels are defined deterministically. For $T=1$, the discontinuous financing strategy is equivalent to active debt management according to $\mathrm{ME}$, because the debt levels are defined following a deterministic debt-to-market value ratio $\theta$ at the beginning of every period. The limit $T \rightarrow 0$ displays a continuous adjustment of the debt levels and, therefore, constitutes active debt management according to HP (for more detailed explanations on the marginal cases, see Clubb and Doran 1995, pp. 687, 690; Arnold et al. 2018, p. 165; Arnold et al. 2019 , pp. 352-353). It follows that discontinuous financing can be used to depict a wide range of financing behaviors.

To obtain a valuation equation at the valuation date, we assume passive debt management in the explicit forecast phase and deduce

$$
\begin{aligned}
V_{0}^{\ell, \mathrm{LD}}= & \sum_{t=1}^{T} \frac{\mathbb{E}\left[\widetilde{F C F}_{t}\right]}{\left(1+\rho^{u}\right)^{t}}+\sum_{t=1}^{T} \frac{\tau \cdot r \cdot D_{t-1}}{(1+r)^{t}} \\
& +\frac{\widetilde{\mathbb{E}\left[\widetilde{F C F}_{T+1}\right]}}{\left(\rho^{u}-g\right) \cdot\left(1+\rho^{u}\right)^{T}} \cdot \frac{1}{1-\theta \cdot \Gamma^{T, g}} .
\end{aligned}
$$

In the first two terms, the market value of the levered firm in the explicit forecast 
phase is determined analogously to valuation Eq. (1) of L-hybrid financing. In the third term, the value of the firm at the beginning of the steady-state phase is calculated according to Eq. (12) and is discounted to the valuation date using the cost of equity of an unlevered firm.

The disadvantage of L-hybrid financing can be transferred to L-discontinuous financing: the debt level that is defined at the beginning of the steady-state phase according to discontinuous financing $\widetilde{D}_{T}=\theta \cdot \widetilde{V}_{T}^{\ell, \mathrm{LD}}$ can deviate considerably from the deterministically defined debt level $D_{T-1}$. Thus, the determination of the debtto-market value ratio at the time of valuation implies that possibly unrealizable refinancing must be carried out at the end of the last period of the explicit forecast phase. This can be compensated by D-discontinuous financing in whichanalogously to D-hybrid financing-the debt level of period $T$ is defined deterministically. It follows that no substantial refinancing is required at the beginning of the steady-state phase. However, in period $2 T, 3 T$, and so on, refinancing is still required; but since the firm is in a steady state in these periods, we consider these refinancing activities as less severe. To derive a valuation equation for D-discontinuous financing, we use the deterministically defined debt level $D_{T}$ instead of $\theta \cdot \mathbb{E}\left[\widetilde{V}_{T}^{\ell}\right]$ in Eq. (7) and apply an analogous relationship, as in Eq. (10). At the end of the explicit forecast phase, we obtain

$$
\begin{aligned}
\mathbb{E}\left[\widetilde{V}_{T}^{\ell, \mathrm{DD}}\right]= & \mathbb{E}\left[\widetilde{F C F}_{T+1}\right] \cdot \operatorname{APV}\left(\rho^{u}, g, T\right)+\tau \cdot r \cdot D_{T} \cdot \operatorname{APV}(r, g, T) \\
& +\frac{\mathbb{E}\left[\widetilde{V}_{T}^{\ell, \mathrm{DD}}\right] \cdot(1+g)^{T}}{\left(1+\rho^{u}\right)^{T}},
\end{aligned}
$$

which can be simplified by solving the circularity problem to

$$
\mathbb{E}\left[\widetilde{V}_{T}^{\ell, \mathrm{DD}}\right]=\frac{\mathbb{E}\left[\widetilde{F C F}_{T+1}\right] \cdot \operatorname{APV}\left(\rho^{u}, g, T\right)+\tau \cdot r \cdot D_{T} \cdot \operatorname{APV}(r, g, T)}{1-\frac{(1+g)^{T}}{\left(1+\rho^{u}\right)^{T}}},
$$

where the abbreviation DD stands for D-discontinuous financing. This expression can be further reduced, similar to L-discontinuous financing, using the factor $\Gamma^{T, g}$, see Eq. (13), to

$$
\mathbb{E}\left[\widetilde{V}_{T}^{\ell, \mathrm{DD}}\right]=\mathbb{E}\left[\widetilde{V}_{T}^{u}\right]+D_{T} \cdot \Gamma^{T, g} .
$$

Contrary to L-discontinuous financing, this valuation equation contains the deterministic debt level $D_{T}$ instead of the debt-to-market value ratio $\theta$. Furthermore, it is an additive instead of a multiplicative composition between the value of the unlevered firm and the factor $\Gamma^{T, g}$. This is because, in the case of D-discontinuous financing, the value of the tax shield does not contain the value of the levered firm, such that its calculation does not involve a circularity problem. In the explicit forecast phase, we again assume passive debt management, which yields at the valuation date 


$$
\begin{aligned}
V_{0}^{\ell, \mathrm{DD}}= & \sum_{t=1}^{T} \frac{\mathbb{E}\left[\widetilde{F C F}_{t}\right]}{\left(1+\rho^{u}\right)^{t}}+\sum_{t=1}^{T} \frac{\tau \cdot r \cdot D_{t-1}}{(1+r)^{t}} \\
& +\frac{\mathbb{E}\left[\widetilde{F C F}_{T+1}\right]}{\left(\rho^{u}-g\right) \cdot\left(1+\rho^{u}\right)^{T}}+\frac{D_{T} \cdot \Gamma^{T, g}}{(1+r)^{T}} .
\end{aligned}
$$

The first three terms correspond to valuation Eq. (2) of D-hybrid financing. Only the calculation of the terminal value of the tax shields in the last term differs since discontinuous financing instead of active debt management is used in the steadystate phase. The deduced value of the tax shield at the beginning of the steady-state phase, see Eq. (17), is discounted to the valuation date using the risk-free interest rate, since it depends only on the debt level $D_{T}$, which is defined deterministically at the valuation date.

If the emerging debt-to-market value ratio of D-discontinuous financing $\frac{D_{T}}{\mathbb{\sim} \widetilde{V}_{T}, \mathrm{DD}}$ coincides with the deterministic debt-to-market value ratio $\theta$ of L-discontinuous financing, we again obtain the same results for both financing strategies at the beginning of the steady-state phase, that is,

$$
\mathbb{E}\left[\tilde{V}_{T}^{\ell, \mathrm{LD}}\right]=\mathbb{E}\left[\widetilde{V}_{T}^{\ell, \mathrm{DD}}\right] .
$$

To obtain the relationship at the valuation date, we again exclude the explicit forecast phase. Analogous to hybrid financing, the terminal values of the tax shields are discounted differently to the valuation date such that the terminal value of the levered firm in the case of D-discontinuous financing is higher than in the case of Ldiscontinuous financing at the valuation date, that is,

$$
T V_{0}^{\ell, \mathrm{DD}}>T V_{0}^{\ell, \mathrm{LD}} \text {. }
$$

Table 2 summarizes these results. In the next section, we compare L- and D-discontinuous financing with L- and D-hybrid financing and conduct simulations to illustrate the differences in firm value.

\section{Comparison of mixed financing strategies in a two-phase model}

\subsection{Theoretical comparison of mixed financing strategies in a two-phase model}

In the previous section, we compared L- and D-hybrid financing, as well as L- and D-discontinuous financing. Now we compare these financing policies among each other to outline value differences that occur at the beginning of the steady-state phase and at the valuation date. We start with differences of the terminal values at time $T$. These differences result from different assumptions about the financing strategy of the steady-state phase. If discontinuous financing is assumed, the tax shields are certain within a planning phase and, therefore, can be discounted at the risk-free interest rate for $T$ periods. Otherwise, if active debt management according 
Table 2 Comparison of the terminal values of the unlevered firm, the tax shields and the levered firm under L- and D-discontinuous financing for the case of coinciding debt-to-market value ratios at time $T$ and at the valuation date

\begin{tabular}{|c|c|c|c|c|}
\hline & & \multicolumn{2}{|l|}{ LD } & $\mathrm{DD}$ \\
\hline \multicolumn{5}{|c|}{ Time $T$} \\
\hline & $\begin{array}{l}\text { TV unlevered } \\
\text { firm }\end{array}$ & $\mathbb{E}\left[\widetilde{V}_{T}^{u}\right]$ & $=$ & $\mathbb{E}\left[\widetilde{V}_{T}^{u}\right]$ \\
\hline+ & TV tax shields & $\mathbb{E}\left[\widetilde{V}_{T}^{T S, \mathrm{LD}}\right]$ & $=$ & $V_{T}^{T S, \mathrm{DD}}$ \\
\hline$=$ & TV levered firm & $\mathbb{E}\left[\widetilde{V}_{T}^{\ell, \mathrm{LD}}\right]$ & $=$ & $\mathbb{E}\left[\widetilde{V}_{T}^{\ell, \mathrm{DD}}\right]$ \\
\hline \multirow{2}{*}{\multicolumn{2}{|c|}{$\begin{array}{l}\text { TV TS is discounted at } \\
\text { Time } 0\end{array}$}} & $\rho^{u}$ & & $r$ \\
\hline & & & & \\
\hline & $\begin{array}{l}\text { TV unlevered } \\
\text { firm }\end{array}$ & $T V_{0}^{u}$ & $=$ & $T V_{0}^{u}$ \\
\hline+ & TV tax shields & $T V_{0}^{T S, \mathrm{LD}}$ & $<$ & $T V_{0}^{T S, \mathrm{DD}}$ \\
\hline$=$ & TV levered firm & $T V_{0}^{\ell, \mathrm{LD}}$ & $<$ & $T V_{0}^{\ell, \mathrm{DD}}$ \\
\hline
\end{tabular}

to $\mathrm{ME}$ is used, the tax shields are certain only in the period of their emergence and can be discounted at the risk-free interest rate for only one period. Under active debt management according to HP, the adjustment occurs continuously such that all tax shields are discounted at the unlevered cost of equity. The longer the tax shields can be discounted at the risk-free interest rate, the higher is the value of the tax shields. For an explicit forecast phase, and therefore planning phases, that are composed of more than one period, that is, $T>1$, follows that the terminal value of the tax shields is ceteris paribus higher in the case of discontinuous financing than in the case of active debt management of ME or HP which is used for hybrid financing. We obtain

$$
\mathbb{E}\left[\widetilde{V}_{T}^{T S, \mathrm{D}}\right]>\mathbb{E}\left[\widetilde{V}_{T}^{T S, \mathrm{H}}\right],
$$

where $\mathrm{D}$ and $\mathrm{H}$ shorten discontinuous and hybrid financing, respectively. Since the terminal value of the unlevered firm is independent of the financing policy, the relationship is preserved for the market value of the firm, that is,

$$
\mathbb{E}\left[\widetilde{V}_{T}^{\ell, \mathrm{D}}\right]>\mathbb{E}\left[\widetilde{V}_{T}^{\ell, \mathrm{H}}\right] .
$$

In the case of passive debt management, the debt level of each period is defined deterministically at the valuation date such that all tax shields are certain and can be discounted at the risk-free interest rate. Thus, the terminal value of the tax shields is considerably higher under passive debt management than under discontinuous financing, which yields a higher market value of the firm. Overall, we conclude 
Table 3 Comparison of the terminal values of the unlevered firm, the tax shields and the levered firm under L-hybrid, D-hybrid, L-discontinuous, and D-discontinuous financing for the case of coinciding debt-to-market value ratios at time $T$ and at the valuation date

\begin{tabular}{|c|c|c|c|c|c|c|c|c|}
\hline & & \multicolumn{2}{|l|}{ LH } & \multicolumn{2}{|l|}{$\mathrm{DH}$} & \multicolumn{2}{|l|}{ LD } & DD \\
\hline \multicolumn{9}{|c|}{ Time $T$} \\
\hline & $\begin{array}{l}\text { TV unlevered } \\
\text { firm }\end{array}$ & $\mathbb{E}\left[\widetilde{V}_{T}^{u}\right]$ & $=$ & $\mathbb{E}\left[\widetilde{V}_{T}^{u}\right]$ & $=$ & $\mathbb{E}\left[\widetilde{V}_{T}^{u}\right]$ & $=$ & $\mathbb{E}\left[\widetilde{V}_{T}^{u}\right]$ \\
\hline+ & TV tax shields & $\mathbb{E}\left[\widetilde{V}_{T}^{T S, \mathrm{LH}}\right]$ & $=$ & $V_{T}^{T S, \mathrm{DH}}$ & $<$ & $\mathbb{E}\left[\widetilde{V}_{T}^{T S, \mathrm{LD}}\right]$ & $=$ & $V_{T}^{T S, \mathrm{DD}}$ \\
\hline$=$ & TV levered firm & $\mathbb{E}\left[\widetilde{V}_{T}^{\ell, \mathrm{LH}}\right]$ & $=$ & $\mathbb{E}\left[\widetilde{V}_{T}^{\ell, \mathrm{DH}}\right]$ & $<$ & $\mathbb{E}\left[\widetilde{V}_{T}^{\ell, \mathrm{LD}}\right]$ & $=$ & $\mathbb{E}\left[\widetilde{V}_{T}^{\ell, \mathrm{DD}}\right]$ \\
\hline \multicolumn{2}{|c|}{$\begin{array}{l}\text { TV TS is discounted at } \\
\text { Time } 0\end{array}$} & $\rho^{u}$ & & $r$ & & $\rho^{u}$ & & $r$ \\
\hline & $\begin{array}{l}\text { TV unlevered } \\
\text { firm }\end{array}$ & $T V_{0}^{u}$ & $=$ & $T V_{0}^{u}$ & $=$ & $T V_{0}^{u}$ & $=$ & $T V_{0}^{u}$ \\
\hline+ & TV tax shields & $T V_{0}^{T S, \mathrm{LH}}$ & $<$ & $T V_{0}^{T S, \mathrm{DH}}$ & $?$ & $T V_{0}^{T S, \mathrm{LD}}$ & $<$ & $T V_{0}^{T S, \mathrm{DD}}$ \\
\hline$=$ & TV levered firm & $T V_{0}^{\ell, \mathrm{LH}}$ & $<$ & $T V_{0}^{\ell, \mathrm{DH}}$ & $?$ & $T V_{0}^{\ell, \mathrm{LD}}$ & $<$ & $T V_{0}^{\ell, \mathrm{DD}}$ \\
\hline
\end{tabular}

$$
\begin{aligned}
\mathbb{E}\left[\widetilde{V}_{T}^{\ell, \mathrm{a}}\right] & =\mathbb{E}\left[\widetilde{V}_{T}^{\ell, \mathrm{LH}}\right]=\mathbb{E}\left[\widetilde{V}_{T}^{\ell, \mathrm{DH}}\right] \\
& <\mathbb{E}\left[\widetilde{V}_{T}^{\ell, \mathrm{LD}}\right]=\mathbb{E}\left[\widetilde{V}_{T}^{\ell, \mathrm{DD}}\right] \\
& \ll \mathbb{E}\left[\widetilde{V}_{T}^{\ell, \mathrm{p}}\right],
\end{aligned}
$$

where a and p stand for active and passive debt management, respectively. For this comparison, a consistent assumption regarding active debt management is again necessary. Active debt management of either ME or HP needs to be used for both cases of hybrid financing. The upper half of Table 3 summarizes these findings. The result that the difference between passive debt management, active debt management, and discontinuous financing depends on the length of the planning phases $T$ is not new. It was already illustrated by an example in Arnold et al. (2018). However, they did not consider a two-phase model with a distinction in L- and D-financing. Hence, we expand their example by these aspects and additionally, quantify the influence of the parameter $T$ and the influence of other input parameters in the next section.

It remains to outline deviations of the market values at the valuation date, which are outlined in the lower half of Table 3. All comparisons apply for active debt management of ME and HP. By excluding the explicit forecast phase, we consider again only disparities that result from the discounting of the terminal value depending on whether L- or D-financing is assumed. We start with a comparison of L-hybrid and L-discontinuous financing. In both cases, the entire market value of period $T$ is discounted at the cost of equity of an unlevered firm, see Eqs. (1) and (14), respectively, since the tax shields of the steady-state phase are uncertain. It follows that value differences that occur at the end of the explicit forecast phase are 
transferred to the valuation date such that the terminal value under L-discontinuous financing is higher than that under L-hybrid financing at the valuation date. Considering Eq. (20) yields

$$
T V_{0}^{\ell, \mathrm{DD}}>T V_{0}^{\ell, \mathrm{LD}}>T V_{0}^{\ell, \mathrm{LH}}
$$

Under both D-hybrid and D-discontinuous financing, the terminal value of the tax shields depends on the debt level at time $T$ that is defined deterministically at the valuation date. Thus, the terminal value of the tax shields is certain and can be discounted at the risk-free interest rate; see Eqs. (2) and (18). The value advantage of discontinuous financing over hybrid financing is again transferred to the valuation date, which yields a higher value under D-discontinuous financing. By additionally considering Eq. (6), we conclude

$$
T V_{0}^{\ell, \mathrm{DD}}>T V_{0}^{\ell, \mathrm{DH}}>T V_{0}^{\ell, \mathrm{LH}} .
$$

Whereas these relationships apply for every specification of the input parameters, the relationship of L-discontinuous and D-hybrid financing is still unclear. Although the terminal value under L-discontinuous financing is always higher than that under D-hybrid financing at the beginning of the steady-state phase, see Eq. (22), this value advantage of L-discontinuous financing is countered by the value advantage of D-hybrid financing through the discounting of the terminal value of the tax shields to the valuation date at the risk-free interest rate. Depending on which effect is dominant, a higher firm value under L-discontinuous financing is conceivable and vice versa. Furthermore, it remains unclear whether the outlined differences are severe or negligible, that is, whether these theoretical findings have a considerable impact on the market value. In the following subsection, we conduct a simulation analysis to analyze the distribution of the deviations between the different financing strategies and to quantify the influence of all input parameters. This analysis enables us to draw conclusions under which conditions these mixed financing are relevant for the practice of corporate valuation.

\subsection{Simulation analysis}

In this subsection, we use a Monte Carlo simulation to analyze the distribution of the theoretically outlined differences in the market value of the firm and the sensitivity of input parameters to illustrate the economic relevance. We assume a population of 100,00 firms that pursue mixed financing. We model the necessary input parameters as independent and uniformly distributed as follows. For the firms' unlevered cost of equity, cost of debt, and corporate tax rate, we define $\rho^{u} \sim U[8 \% ; 12 \%], r \sim U[2 \% ; 5 \%]$, and $\tau \sim U[25 \% ; 35 \%]$, respectively. We assume a consistent debt-to-market value ratio for all financing strategies, which is distributed according to $\theta \sim U[40 \% ; 80 \%]$. For D-hybrid and D-discontinuous financing, we determine again the debt level $D_{T}$ such that the debt-to-market value ratio that results from this debt level and the uncertain market value at the end of the explicit forecast phase equals $\theta$. For the growth rate of the steady-state phase, we suppose $g \sim U[0.5 \% ; 2.0 \%]$ and for the length of the explicit forecast phase, we 
consider $T \sim U\{5 ; 6 ; 7\} .{ }^{3}$ Note that we apply active debt management according to $\mathrm{HP}$ in the case of hybrid financing.

The percentage valuation deviation is defined as

$$
p(A, B)=\frac{T V_{0}^{\ell, A}-T V_{0}^{\ell, B}}{T V_{0}^{\ell, B}},
$$

where $A, B \in\{\mathrm{H}, \mathrm{LH}, \mathrm{DH}, \mathrm{D}, \mathrm{LD}, \mathrm{DD}\}$. We need not specify the value of the FCF since it does not affect the valuation deviation. In the simulation, we analyze the distribution of the percentage valuation deviation by computing the mean, the standard deviation, the minimum, and the maximum. Moreover, we quantify the influence of the input parameters on this deviation. Particularly, we use Spearman's rank correlation coefficient (Charnes 2007, pp. 63-65) to analyze which parameters influence this deviation the most and which the least. Table 4 summarizes the results.

As outlined above, at the beginning of the steady-state phase, the values of L- and D-financing coincide. Thus, at time $T$ we need only compare the values of hybrid and discontinuous financing. As illustrated in the previous subsection, the value under discontinuous financing is higher than that under hybrid financing. For the outlined intervals, we obtain a minimal deviation of $0.6 \%$ and a maximal deviation of $4.3 \%$ with a mean of $1.7 \%$. The debt-to-market value ratio $\theta$ has the greatest influence on this difference. The correlation coefficient amounts to more than $50 \%$. If a firm pursues a high debt ratio, the importance of the value of the tax shields increases. Furthermore, the length of the explicit forecast phase $T$, which determines the length of the planning phases, has the second biggest influence, namely around $16 \%$. For a high value of $T$, the planning phases are longer such that the difference of the number of periods for which the tax shields are certain becomes larger. By comparison, the other value drivers of the tax shields, the risk-free interest rate $r$ and the tax rate $\tau$, account for $14.2 \%$ and $11.7 \%$ of the valuation deviation, respectively. A higher value of $r$ and $\tau$ increases the tax shields. The growth rate $g$ and unlevered cost of equity $\rho^{u}$ each has a sensitivity of under $4 \%$, which is a negligible effect.

At the valuation date, we compare each one of the presented mixed financing strategies with every other mixed financing strategy. The results are also outlined in Table 4. We obtain similar deviations for a comparison of L- and D-hybrid or L- and D-discontinuous financing, for which we obtain an average deviation of $3.1 \%$ and $3.8 \%$, respectively. In both cases, the debt-to-market value ratio $\theta$ and the length of the explicit forecast phase $T$ are most important. The higher the debt-to-market value ratio and the longer the planning phases, the higher terminal value of the tax shields. Furthermore, the longer the explicit forecast phase, the larger the value advantage of D-financing over L-financing. The influence of every other parameter is considerably smaller.

\footnotetext{
3 The length of the explicit forecast phase is company-specific and should be extended until the assumption of a steady state seems realistic (Ballwieser and Hachmeister 2016, p. 52). Brealey et al. (2020) assume a length of six periods (Brealey et al. 2020, p. 97) and (Koller et al. 2015) recommend five to seven periods (Koller et al. 2015, p. 230), which is why we decided on this distribution for $T$.
} 


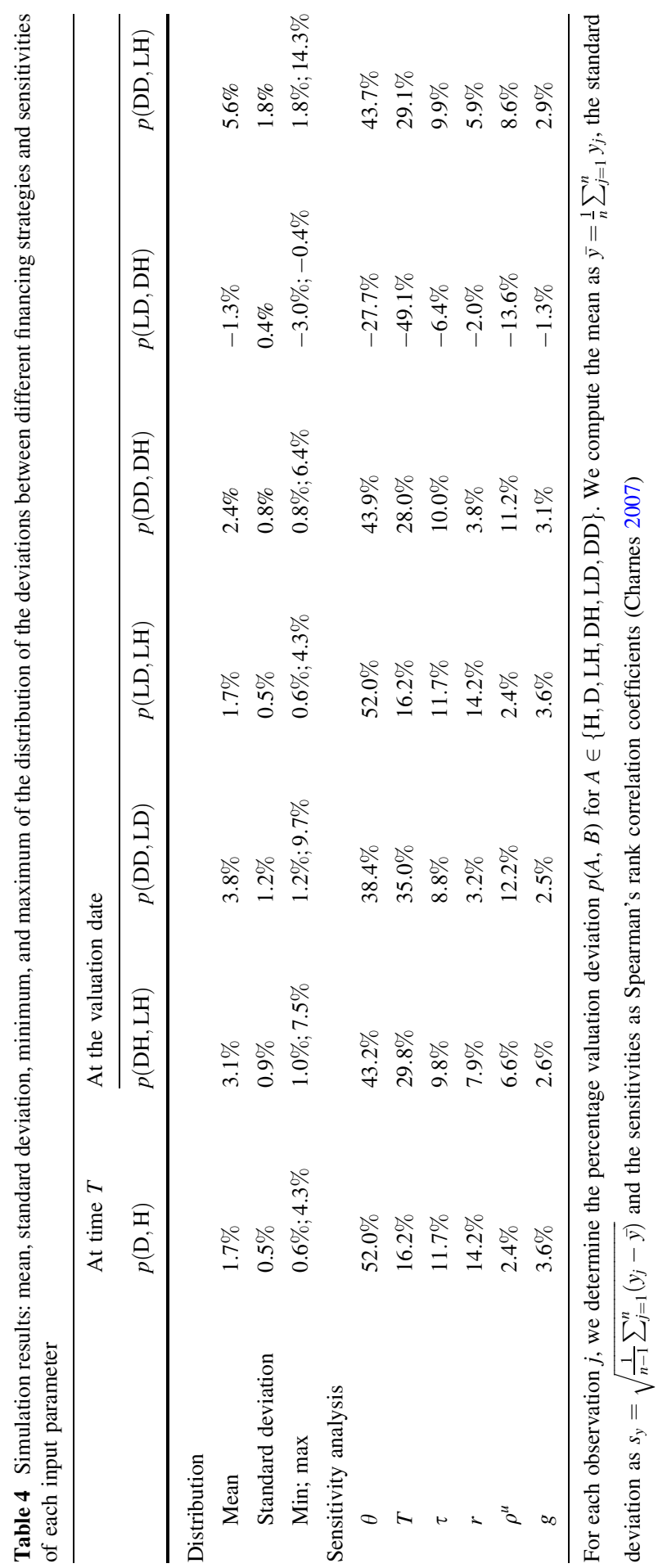


Under L-financing, both the terminal value of the unlevered firm and the terminal value of the tax shields are discounted at the cost of equity of the unlevered firm to obtain the value at the valuation date. It follows that comparing L-hybrid and Ldiscontinuous financing at the valuation date yields the same deviations as a comparison of hybrid and discontinuous financing at time $T$. Comparing D-hybrid and D-discontinuous financing shows a larger valuation deviation of between $0.8 \%$ and $6.4 \%$. Again, the debt-to-market value ratio $\theta$ has the highest impact, of about $44 \%$, followed by the length of the explicit forecast phase, which explains about $28 \%$. The remarkable higher sensitivity of $T$, compared to the deviation of L-hybrid and L-discontinuous financing, is due to an increasing importance of the length of the explicit forecast phase since the terminal value of the tax shields is discounted at the risk-free interest rate.

In the previous Sect. 3.1, we were not able to make a general statement about the relationship of D-hybrid and L-discontinuous financing. However, our simulations show that for the specified definition areas, the market value under D-hybrid financing is always higher than that under L-discontinuous financing. The percentage valuation deviation has a mean of $-1.3 \%$ and a standard deviation of $0.4 \%$. The length of the explicit forecast phase has the highest impact, accounting for lmost $50 \%$ of the valuation deviation. It follows that the discounting of the terminal value of the tax shields to the valuation date at the risk-free interest rate for $T$ periods has a high impact and compensates for the value advantage of L-discontinuous financing at the beginning of the steady-state phase. For other specifications of the parameters, a value advantage of L-discontinuous financing is conceivable but not plausible. For example, for an unusual short explicit forecast phase that comprises only one period and otherwise unaffected definition ranges, we find that the market value under L-discontinuous financing is always higher than that under D-hybrid financing. For an explicit forecast phase of length two, there are only very few parameter constellations for which the market value under L-discontinuous financing is higher; and for an explicit forecast phase of three periods, there are no constellations where this case appears any more. It follows that under most parameter ranges, we record that the market value under D-hybrid financing is higher than that under L-discontinuous financing.

The value differences become considerably larger if we compare L-hybrid and Ddiscontinuous financing, whereby we deduce valuation deviations of almost $15 \%$. Whereas the deviations that occur in a comparison of L-discontinuous financing and hybrid financing are negligible, a deviation of more than $10 \%$ can be considered economically relevant. Even deviations of $7.5 \%$ or $9.7 \%$, as in the comparisons of L- and D-hybrid or L- and D-discontinuous financing, respectively, can lead to considerable disparities.

The results that the debt-to-market value ratio and the length of the planning phases have the highest influence are not surprising. If a firm had no or only little debt financing and no or very short planning phases of passive debt management, there would not be significant deviations. However, we were able to describe the distributions of the deviations and the influences of these parameters. Furthermore, to be able to analyze for which length of planning phases our model is economically 


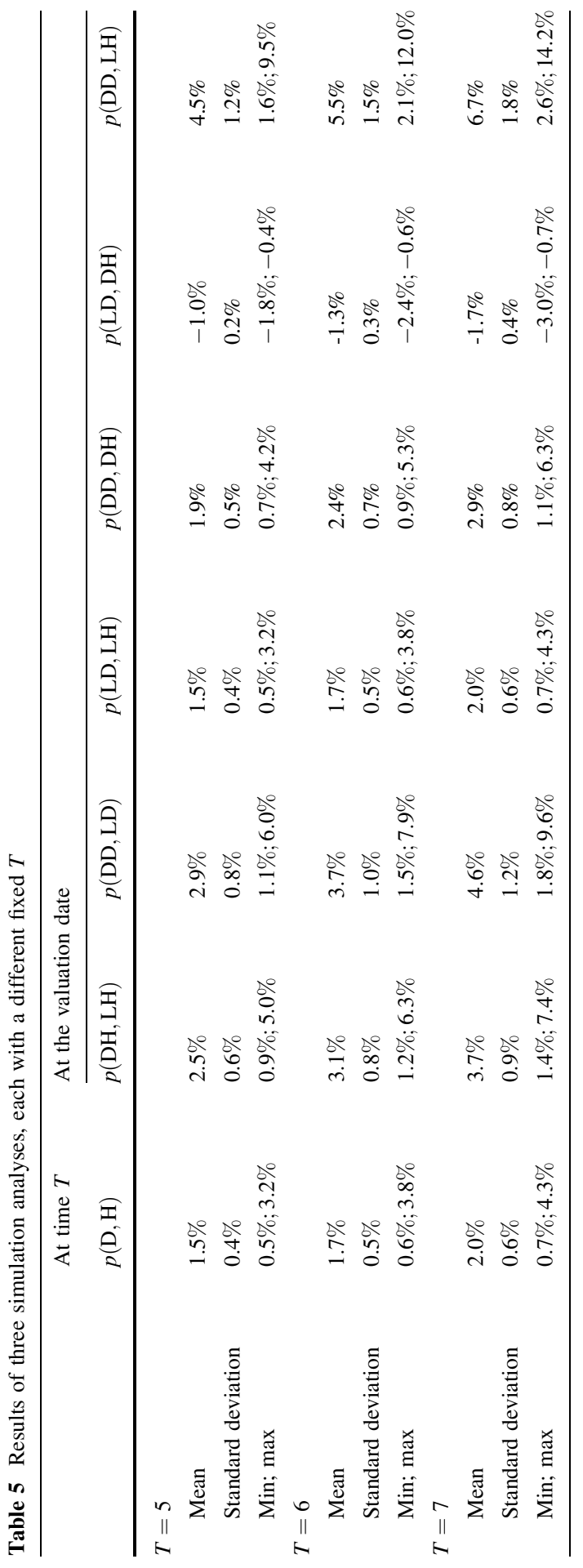


relevant, we conducted the above simulation three more times each with a different fixed $T$. The results can be found in Table 5 .

The deviations increase for longer planning phases, that is, for a larger $T$ but even in the simulation with $T=5$, we obtain deviations of up to $9.5 \%$. For planning phases of length $T=7$, we obtain deviations of more than $5 \%$ in almost all comparisons. Overall, we conclude that especially for firms with a high leverage and a long explicit forecast phase the outlined deviations should be examined carefully and the analyzed mixed financing strategies should be considered for the valuation to depict a wide range of financing behavior.

\section{Conclusions}

Empirical research indicates that active or passive debt management as pure financing strategies can explain the capital structure decisions of firms only to a limited extent. In response, corporate valuation theory has introduced various forms of mixed financing strategies. In this study, we analyzed discontinuous financing and hybrid financing as the main mixed financing policies and clarified their use and impacts on the market value in a two-phase model.

With passive debt management in the explicit forecast phase and active debt management in the steady-state phase, hybrid financing is directly linked to the twophase model. Discontinuous financing, on the contrary, is characterized by the possibility of refinancing according to updated expected market values after a certain number of periods, independently of the separation of the planning horizon into two phases. To use this mixed financing strategy in a two-phase model, we linked the number of periods after which a refinancing can be carried out to the number of periods of the explicit forecast phase. Therefore, at the end of the explicit forecast phase with $T$ periods and, accordingly, at the end of every $T$ periods, the firm has the option of refinancing. This study improved the comprehensibility of the previous derivation of a valuation equation under discontinuous financing by applying a simpler and more intuitive recursive valuation approach.

Analogous to L- and D-hybrid financing, we differentiated between L- and D-discontinuous financing. On the one hand, under L-hybrid and L-discontinuous financing, the leverage of the steady state is defined at the time of valuation. On the other hand, under D-hybrid and D-discontinuous financing, the debt-to-market value ratio that results from the deterministic debt level and the uncertain market value at the end of the explicit forecast phase is used. The difference between these financing policies lies in the necessity for refinancing at the end of the explicit forecast phase. In the case of L-hybrid and L-discontinuous financing, the debt level at the end of the explicit forecast phase has to be adjusted according to the deterministic leverage. By contrast, this is not necessary in the case of D-hybrid and D-discontinuous financing, since the debt level is defined deterministically at the valuation date. However, in this case, the leverage of the steady state is uncertain at the valuation date.

Furthermore, we showed that differences occur if a firm's financing behavior corresponds to one of these mixed financing strategies but a pure financing strategy 
is applied in the valuation. The difference is smaller if pure active debt management is used instead of pure passive debt management. The comparison of the four mixed financing strategies yields the result that for a consistent debt-to-market value ratio, the terminal values at the beginning of the steady state coincide in the case of L- and D-hybrid financing and in the case of L- and D-discontinuous financing. Due to the greater uncertainty of the tax shields in the case of hybrid financing, the terminal value under this financing policy is lower than that under discontinuous financing. Regarding the market values at the valuation date, we elucidated that this difference is transferred in the case of D- or L-financing. It follows that the market value under D-discontinuous financing is higher than that under D-hybrid financing. Analogously, the market value under L-discontinuous financing is higher than the market value under L-hybrid financing. Only the relationship of D-hybrid and L-discontinuous financing remained unclear. However, for most cases, we found that D-hybrid financing yields a higher firm value than L-discontinuous financing does.

The differences between the mixed financing strategies become larger if the leverage increases or the explicit forecast phase becomes longer. Therefore, especially when the leverage is high and the explicit forecast phase is long, the deviations between the terminal values can be considerable, since they can amount to more than $10 \%$. In these cases, one should examine a firm's financing strategy carefully and consider the application of a mixed financing strategy to avoid valuation inaccuracies. It follows that the valuation formulas presented in this study could offer a valuable alternative for corporate valuation practice to better reflect the financing behavior of firms and could lead to a more sophisticated valuation result. Thus, the analysis in this study contributes to both the practice and the theory of corporate valuation.

Further research could address other forms of mixed financing strategies. These could be generated by combining passive and active debt management differently, or by replacing passive or active debt management with other pure financing strategies. In addition, a mixed financing strategy that consists of more than two pure financing strategies is conceivable. Moreover, one could consider adding an additional phase to secure the transition from the explicit forecast phase to the steady state. In such a three-phase model, it would be possible, for example, to use the simultaneous mixed financing of Dierkes and Schäfer (2017) to obtain a gradual transition from passive debt management to the financing strategy of the steadystate phase. Furthermore, the assumption that debt is risk-free can be relaxed. Arnold et al. (2019) show that for longer planning phases, the probability of default increases and outline ideas on how to consider this in the valuation. Thus, further research could also attempt to develop a model that includes the costs of financial distress and the probability of default for these mixed financing strategies.

Open Access This article is licensed under a Creative Commons Attribution 4.0 International License, which permits use, sharing, adaptation, distribution and reproduction in any medium or format, as long as you give appropriate credit to the original author(s) and the source, provide a link to the Creative Commons licence, and indicate if changes were made. The images or other third party material in this article are included in the article's Creative Commons licence, unless indicated otherwise in a credit line to the material. If material is not included in the article's Creative Commons licence and your intended use is not permitted by statutory regulation or exceeds the permitted use, you will need to obtain 
permission directly from the copyright holder. To view a copy of this licence, visit http:// creativecommons.org/licenses/by/4.0/.

\section{References}

Arnold, S., A. Lahmann, and B. Schwetzler. 2018. Discontinuous financing based on market values and the value of tax shields. Business Research 11 (1): 149-171.

Arnold, S., A. Lahmann, M. Schreiter, and B. Schwetzler. 2019. Finanzierungspolitiken, Tax Shield und Insolvenz in der Unternehmensbewertung-ein integrativer Ansatz. WPg 72 (6): 351-359.

Ashton, D.J., and D.R. Atkins. 1978. Interactions in corporate financing and investment decisionsimplications for capital budgeting: A further comment. The Journal of Finance 33 (5): 1447-1453.

Ballwieser, W., and D. Hachmeister. 2016. Unternehmensbewertung, 5th edn. Schäffer-Poeschel Verlag.

Barclay, M.J., and C.W. Smith. 2005. The capital structure puzzle: The evidence revisited. Journal of Applied Corporate Finance 17 (1): 8-17.

Baule, R. 2019. The cost of debt capital revisited. Business Research 12 (2): 721-753.

Berk, J., and P. DeMarzo. 2017. Corporate Finance, 4th ed. Essex: Pearson.

Bhamra, H.S., L.A. Kuehn, and I.A. Strebulaev. 2010. The aggregate dynamics of capital structure and macroeconomic risk. The Review of Financial Studies 23 (12): 4187-4241.

Brealey, R.A., S.C. Myers, and F. Allen. 2020. Principles of Corporate Finance, 13th ed. New York: McGraw-Hill.

Brounen, D., A. de Jong, and K. Koedijk. 2006. Capital structure policies in Europe: Survey evidence. Journal of Banking \& Finance 30 (5): 1409-1442.

Charnes, J. 2007. Financial Modelling with Crystal Ball and Excel, 1st ed. Hoboken: Wiley.

Clubb, C.D., and P. Doran. 1995. Capital budgeting, debt management and the APV criterion. Journal of Business Finance \& Accounting 22 (5): 681-694.

Copeland, T.E., J.F. Weston, and K. Shastri. 2014. Financial Theory and Corporate Policy, 4th ed. Harlow: Pearson.

de Jong, A., and P. Verwijmeren. 2010. To have a target debt ratio or not: What difference does it make? Applied Financial Economics 20 (3): 219-226.

Dierkes, S., and H.C. Gröger. 2010. Hybride Finanzierungspolitiken in der Unternehmensbewertung. Corporate Finance 1 (1): 59-64.

Dierkes, S., and U. Schäfer. 2017. Corporate taxes, capital structure, and valuation: Combining Modigliani/Miller and Miles/Ezzell. Review of Quantitative Finance and Accounting 48 (2): 363-383.

Fama, E.F., and K.R. French. 2002. Testing trade-off and pecking order predictions about dividends and debt. The Review of Financial Studies 15 (1): 1-33.

Glover, B. 2016. The expected cost of default. Journal of Financial Economics 119 (2): 284-299.

Graham, J.R. 2000. How big are the tax benefits of debt? The Journal of Finance 55 (5): 1901-1941.

Graham, J.R., and C.R. Harvey. 2001. The theory and practice of corporate finance: Evidence from the field. Journal of Financial Economics 60 (2-3): 187-243.

Graham, J.R., and M.T. Leary. 2011. A review of empirical capital structure research and directions for the future. Annual Review of Financial Economics 3: 309-345.

Graham, J.R., M.T. Leary, and M.R. Roberts. 2015. A century of capital structure: The leveraging of corporate America. Journal of Financial Economics 118 (3): 658-683.

Grinblatt, M., and J. Liu. 2008. Debt policy, corporate taxes, and discount rates. Journal of Economic Theory 141 (1): 225-254.

Harris, R.S., and J.J. Pringle. 1985. Risk adjusted discount rates-extensions from the average-risk case. Journal of Financial Research 8 (3): 237-244.

Huang, R., and J.R. Ritter. 2009. Testing theories of capital structure and estimating the speed of adjustment. Journal of Financial and Quantitative Analysis 44 (2): 237-271.

Kayhan, A., and S. Titman. 2007. Firms' histories and their capital structures. Journal of Financial Economics 83 (1): 1-32.

Koller, T., M. Goedhart, and D. Wessels. 2015. Valuation-Measuring and Managing the Value of Companies, 6th ed. Hoboken: Wiley.

Krause, M.V., and A. Lahmann. 2016. Reconsidering the appropriate discount rate for tax shield valuation. Journal of Business Economics 86 (5): 477-512. 
Kruschwitz, L., and A. Löffler. 2020. Stochastic Discounted Cash Flow: A Theory of the Valuation of Firms, 2nd ed. Cham: Springer.

Kruschwitz, L., A. Lodowicks, and A. Löffler. 2005. Zur Bewertung insolvenzbedrohter Unternehmen. Die Betriebswirtschaft 65: 221-236.

Kruschwitz, L., A. Löffler, and D. Canefield. 2007. Hybride Finanzierungspolitik und Unternehmensbewertung. Finanz Betrieb 9 (7/8): 427-431.

Leary, M.T., and M.R. Roberts. 2005. Do firms rebalance their capital structures? The Journal of Finance 60 (6): 2575-2619.

Lewellen, W.G., and D.R. Emery. 1986. Corporate debt management and the value of the firm. The Journal of Financial and Quantitative Analysis 21 (4): 415-426.

Miles, J.A., and J.R. Ezzell. 1980. The weighted average cost of capital, perfect capital markets, and project life: A clarification. The Journal of Financial and Quantitative Analysis 15 (3): 719-730.

Miles, J.A., and J.R. Ezzell. 1985. Reformulating tax shield valuation: a note. The Journal of Finance 40 (5): 1485-1492.

Molina, C.A. 2005. Are firms underleveraged? an examination of the effect of leverage on default probabilities. The Journal of Finance 60 (3): 1427-1459.

Rapp, M.S. 2006. Die arbitragefreie Adjustierung von Diskontierungssätzen bei einfacher Gewinnsteuer. Schmalenbachs Zeitschrift für betriebswirtschaftliche Forschung 58 (6): 771-806.

Sick, G.A. 1990. Tax-adjusted discount rates. Management Science 36 (12): 1432-1450. 